\title{
Immune Complex Glomerulonephritis in Leprosy
}

\author{
A. S. ÇÖLOĞLU* \\ Department of Pathology, Faculty of Dentistry, \\ University of Istanbul, Turkey
}

\begin{abstract}
Twenty patients with lepromatous or borderline leprosy selected at random were investigated for evidence of immune complex glomerulonephritis. Light, immunofluorescence and electron microscopy findings suggested that glomerulonephritis in leprosy results from the accumulation of immune complexes in glomeruli. Fluorescence and electron microscopy findings may be attributed to the fact that the deposits are less soluble immune complexes. A comparison was made between glomerulonephritis in the BSA-rabbit system and leprosy.
\end{abstract}

\section{Introduction}

Renal lesions in leprosy have been recognized by Mitsuda and Ogawa in 1937, in an autopsy analysis of 150 cases. Similar findings were also reported by Kean and Childress (1942). Impaired renal functions and abnormal urinary sediment have also been observed in patients with leprosy (Drutz and Gutman, 1973; Gokhale and Kurkure, 1958; Granells, 1968; Gutman et al., 1973; Rea and Levan, 1975; Thomas et al., 1970). After the introduction of percutaneous renal biopsy, the nature of renal lesions was shown by some authors (Bullock et al., 1974; Date and Johny, 1975; Drutz and Gutman, 1972, 1973; Iveson et al., 1975; Johny et al., 1975; Mittal et al., 1972; Sachdev et al., 1969; Shwe, 1971). Renal amyloidosis, interstitial nephritis, pyelonephritis and prolif erative glomerulonephritis were the significant lesions found in these studies. Recently, the immunological basis of the proliferative lesions was studied (Bullock et al., 1974; Date and Johny, 1975; Drutz and Gutman, 1972; Iveson et al., 1975; Shwe, 1971), but the number of patients was inadequate to support the idea. Therefore, we examined a large group of leprosy patients.

The purpose of the present study is to describe the changes seen by light, immunofluorescence and electron microscopy in the glomeruli of leprosy patients, and to get more information about the frequency of immune complex glomerulonephritis in leprosy as well as the dependency of the lesion on ENL reaction of the disease.

${ }^{*}$ Reprint requests to Dr A. S. Çöloğlu, Dişhekimliḡi Fakültesi, Çapa Istanbul, Turkey.

Received for publication 5 March, 1979.

$0305-7518 / 79 / 030213+10 \$ 01.00 / 0$

○ 1979 British Leprosy Relief Association 


\section{Patients and Methods}

From the patients admitted to the Bakırkoy Leprosy Sanatorium, of different clinical types with or without ENL and varying stages of therapy, 27 were selected at random. They were classified into lepromatous and borderline lepromatous groups according to the Ridley-Jopling immunological method. Twenty-four hour urine and blood samples of these patients were examined for proteinuria, urinary sediment, urea and creatinin clearance and electrolytes. ASTO levels in the sera were also determined. Percutaneous renal biopsy was performed with a Vim-Silvermann needle. The specimen was trisected for light, immunofluorescence and electron microscopy.

Paraffin sections from the specimens were stained with haematoxylin eosin, PAS, PASM, Cresyl violet, Masson's trichrome stain, and TRIFF.

Cryostat sections of the unfixed material about $5 \mu \mathrm{m}$ in thickness were washed for 10 min in Coons' buffer ( $\mathrm{pH} \mathrm{7)}$ and incubated for $30 \mathrm{~min}$ in a moist chamber with rabbit-anti-human gamma globulin G,M,A, and anticomplement conjugated with FITC. The preparations were examined by dark field fluorescent microscopy using a Zeiss photomicroscope equipped with an ultraviolet high pressure mercury lamp (HBO $200 \mathrm{~W}$, barrier filter 244).

For electron microscopy, the tissues were fixed by immersion in $3 \%$ glutaraldehyde. They were then rinsed, postfixed in $1 \%$ osmium tetroxide in a Veronal acetate buffer, dehydrated in acetone and embedded in Vestopal-W. Sections were cut on a LKB ultratome. Survey sections were stained with Toluidine blue and examined by light microscopy. Ultrathin sections were picked up on hole grids and stained with uranyl acetate and lead citrate. They were examined in a Zeiss EM 9s-2 microscope.

\section{Results}

Table 1 shows the clinical, laboratory and light microscopy findings of the cases.

Adequate renal biopsy was obtained from 20 patients examined for this study. Sixteen of the 20 patients were males. The ages ranged from 23 to 70 years. Mean duration of disease was 18 years and ranged from 3 to 33 years. All of the patients had been on dapsone therapy. There were 18 cases of lepromatous type and 2 of borderline lepromatous type. Abnormal renal histology was seen in 12 of the 20 patients. Only 7 patients in the lepromatous group had recent history of ENL, and 4 of these patients had abnormal renal histology: 3 mesangioproliferative glomerulonephritis, 1 rapidly progressive glomerulonephritis. The kidney lesions were observed in 7 of the 13 patients without ENL reaction: 5 mesangioproliferative glomerulonephritis, 1 amyloidosis, 1 chronic pyelonephritis. One of the 2 borderline lepromatous group patients had mesangioproliferative glomerulonephritis. Acid-fast bacilli were not observed in the sections stained with TRIFF.

The main laboratory findings of the mesangioproliferative glomerulonephritis were trace proteinuria and haematuria. The patient with rapidly progressive glomerulonephritis had oedema, proteinuria, casts, leucocyturia and hypertension. A nephrotic syndrome was observed in the patient with 
TABLE 1

\begin{tabular}{lcccccc}
\hline Group & $\begin{array}{c}\text { Age; } \\
\text { sex }\end{array}$ & $\begin{array}{l}\text { Type of } \\
\text { disease }\end{array}$ & ENL & Pu & Hu & Lu \\
\hline Proliferative & & & & & & \\
Mesangioproliferative & $46 ; \mathrm{M}$ & $\mathrm{LL}$ & - & $\mathrm{T}$ & + & + \\
& $28 ; \mathrm{M}$ & $\mathrm{LL}$ & + & $\mathrm{T}$ & + & + \\
& $36 ; \mathrm{M}$ & $\mathrm{LL}$ & - & $\mathrm{T}$ & + & + \\
& $53 ; \mathrm{M}$ & $\mathrm{BL}$ & - & $\mathrm{T}$ & + & + \\
& $42 ; \mathrm{F}$ & $\mathrm{LL}$ & + & $\mathrm{T}$ & - & + \\
& $25 ; \mathrm{F}$ & $\mathrm{LL}$ & - & - & + & + \\
& $35 ; \mathrm{F}$ & $\mathrm{LL}$ & - & $\mathrm{T}$ & + & + \\
Rapidly progressive & $32 ; \mathrm{M}$ & $\mathrm{LL}$ & + & $\mathrm{T}$ & + & + \\
Amyloidosis & $48 ; \mathrm{M}$ & $\mathrm{LL}$ & - & $\mathrm{T}$ & + & + \\
Chronic pylonephritis & $34 ; \mathrm{M}$ & $\mathrm{LL}$ & + & 1 & + & + \\
Normal & $35 ; \mathrm{M}$ & $\mathrm{LL}$ & - & 5 & $\mathrm{M}$ & - \\
& $36 ; \mathrm{M}$ & $\mathrm{LL}$ & - & $\mathrm{T}$ & + & + \\
& $31 ; \mathrm{M}$ & $\mathrm{LL}$ & + & - & $\mathrm{M}$ & - \\
& $57 ; \mathrm{M}$ & $\mathrm{LL}$ & - & $\mathrm{T}$ & - & - \\
& $23 ; \mathrm{M}$ & $\mathrm{LL}$ & + & - & $\mathrm{M}$ & - \\
& $46 ; \mathrm{M}$ & $\mathrm{LL}$ & + & - & - & + \\
& $37 ; \mathrm{M}$ & $\mathrm{BL}$ & - & - & - & - \\
& $42 ; \mathrm{M}$ & $\mathrm{LL}$ & - & - & - & - \\
& $46 ; \mathrm{M}$ & $\mathrm{LL}$ & - & - & - & - \\
& $70 ; \mathrm{F}$ & $\mathrm{LL}$ & - & - & - & - \\
\hline
\end{tabular}

Pu: proteinuria; Hu: haematuria; Lu: leucocyturia; T: trace; M: micro.

${ }^{*} \mathrm{gr} / \mathrm{lt}$.

amyloidosis. Pyuria, haematuria and trace proteinuria were found in the patient with chronic pyelonephritis.

(1) PROLIFERATIVE GLOMERULONEPHRITIS (10 patients)

\section{(a) Mesangio proliferative type}

Nine of the patients had mesangioproliferative changes. There was no suggestion of thickening of the GBM. There appeared to be a definite increase in mesangium (Fig. 1). It was not possible to view the small spike-like projections on the epithelial side of the GBM with PASM stain. Most of the glomeruli in the examined cases showed segmental and peripheral (Bowman capsule) adhesions. In two of the cases, protein substances were observed in the tubuli. Interstitium generally appeared to be normal. In the immunofluorescence study, there was a wide variation in the extent of deposition from patient to patient, which appeared to correlate with the histological findings and the clinical course of the disease. All of the accumulations were of granular pattern (Fig. 2). The mesangium appeared to be the most predilected area. In mild cases of mesangial proliferation, staining of the immune deposits was slight (Fig. 3). In more severe cases, granular deposits of IgG, IgM and C3 were seen in the mesangium. IgG, IgM and C3 were observed in all of the 


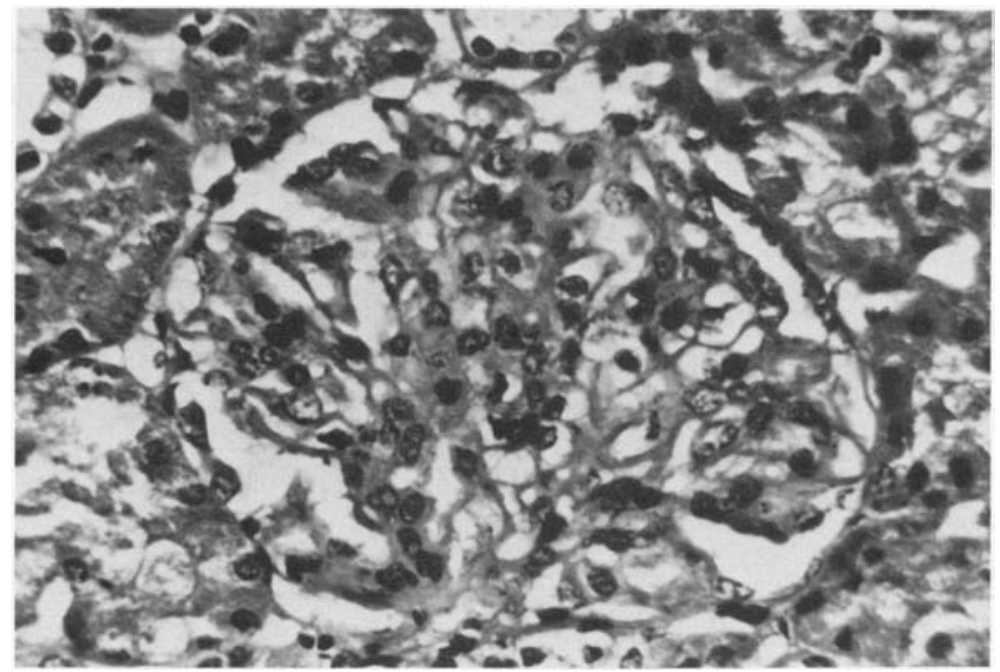

Fig. 1. Increase in matrix material in the mesangium with hypercellularity. (Case from mesangioprolif erative group.) $\mathrm{HE}, \times 500$.

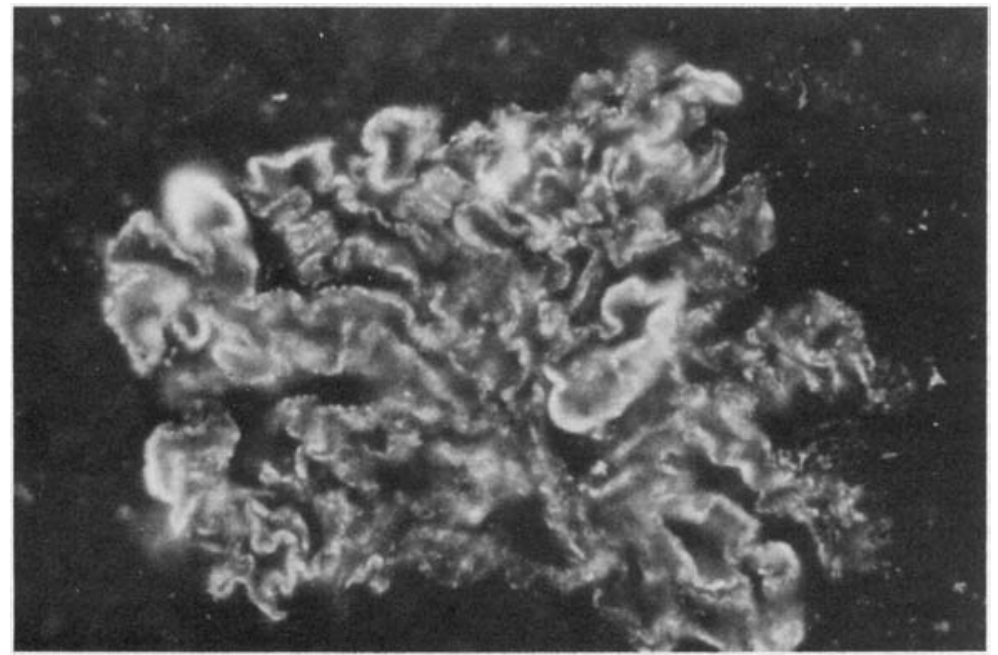

Fig. 2. Irregular deposits occupy the mesangium and occasionally the contiguous portions of the capillary walls. (Case from mesangioprolif erative group.) Antibody specific for IgG, $\times 500$. 


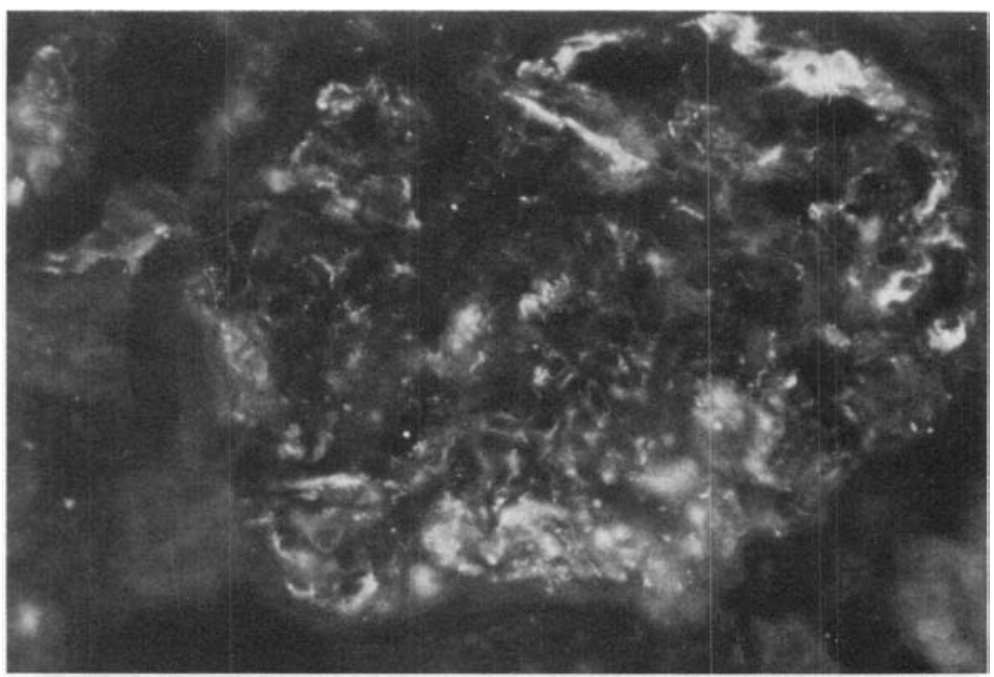

Fig. 3. Granular and patchy distribution of deposits. (Case from mesangioprolif erative group.) Antibody specific for $\mathrm{C} 3, \times 500$.

patients with mesangioproliferative changes. IgA was seen in 2 patients. In one of these cases, IgA was found in the glomeruli, and in the other one, it was observed in the epithelium of the proximal tubuli.

Electron microscopy study showed various structural abnormalities. Proliferation of mesangial cells and increase of mesangial matrix were the prominent findings. Another significant finding was that of electron-dense deposits (Figs 4 and 5). The deposits were seen within the proliferating mesangial matrix with occasional extension into the contiguous basement membrane and between the endothelium and basement membrane. Subepithelial deposits were not observed. There was focal fusion of epithelial foot processes.

\section{(b) Rapidly progressive glomerulonephritis}

One of the patients had severe clinical and laboratory findings. Light microscopy of specimen showed crescent formation in all of the examined glomeruli (Fig. 6). Tubuli were filled with a proteinaceous substance and there were interstitial inflammatory cells. Necrotizing arteritis was not observed. Fluorescence microscopy showed a slight granular staining of IgG and C3, in both mesangium and capillary walls. Electron microscopy failed to demonstrate the electron-dense deposits. The proliferating epithelial cells showed a great increase of cytoplasmic organelles. 


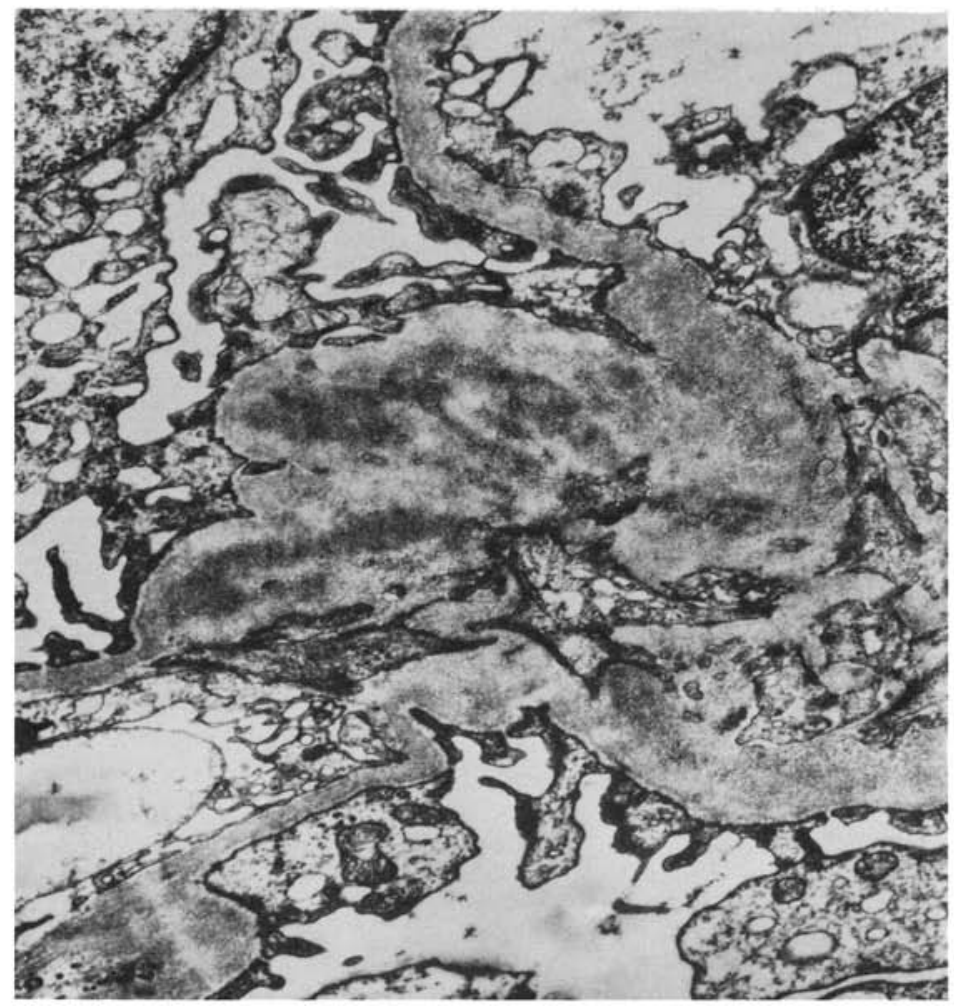

Fig. 4. Electron-dense deposits in an expanded mesangium. These extend for a short distance along the inner aspect of the glomerular loops, and are seen in subendothelial and intramembraneous position. Note the focal fusion of foot processes. (Case from mesangioproliferative group.) $\times 20,000$.

\section{(2) AMYLOIDOSIS (1 patient)}

A pink, homogenous material was seen in the glomeruli and the walls of the arterioles. The substances showed a remarkably positive metachromasia when the section was stained with Cresyl violet. Thus, further study of this case was not commenced.

(3) CHRONIC PYELONEPHRITIS (1 patient)

Two hyalinized glomeruli surrounded with inflammatory cells were seen in the paraffin sections. Other studies were not performed.

\section{Discussion}

Kidney diseases are the most common causes of death in leprosy (Brusco and Masanti, 1963). The main problem is the relationship between disease and 


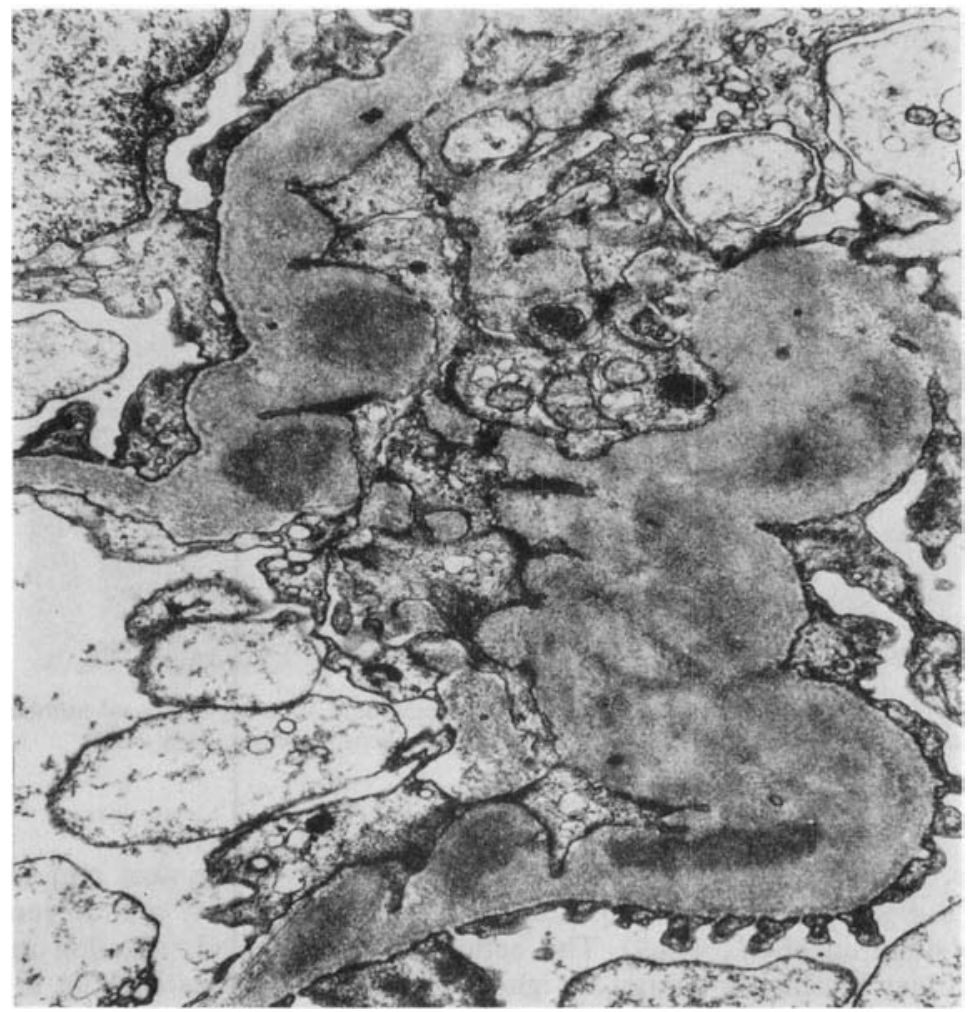

Fig. 5. Mesangial, subendothelial and intramembraneous deposits. (Case from mesangioproliferative group.) $\times 20,000$.

the nephropathy. Much evidence speaks in favour of the existence of two different immunologic mechanisms in experimental as well as human glomerulonephritis. One involves deposition in the glomerular capillary walls and mesangium of antigen-antibody complexes formed in the circulating blood. The principal event in the other mechanism is deposition of antibody in the glomerular capillary walls due to the occurrence in the blood of an antibody which can react with the GBM. The last mechanism seems to be the least common in human glomerulonephritis.

Urine and renal abnormalities in leprosy are reported to be associated with ENL reactions (Bernard, 1971; Brusco and Masanti, 1963; Date and Johny, 1975; Drutz and Gutman, 1972; Gokhale and Kurkure, 1958; Granells, 1968; Gutman et al., 1973; Johny et al., 1975; McAdam et al., 1975; Thomas et al., 1970). Wemambu et al. (1969) suggested that ENL is a manif estation of the Arthus phenomenon. Waters et al. (1971) and Drutz et al. (1973) proposed that ENL is a result of the accumulation of immune complexes. During ENL 


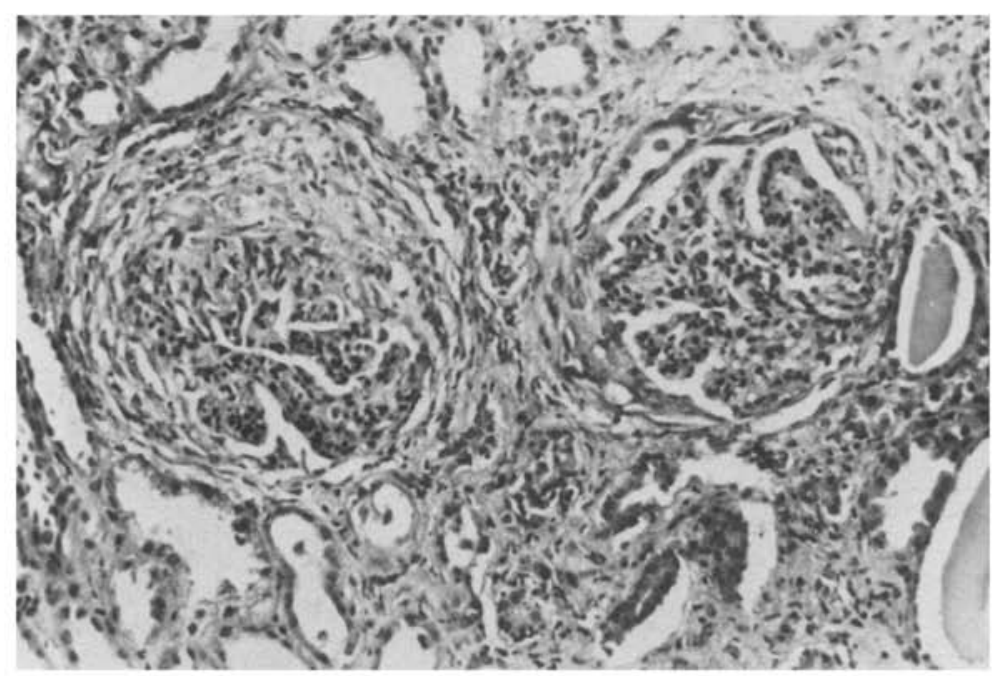

Fig. 6. Epithelial crescents surrounding two glomerular tufts showing increased numbers of mesangial cells. (Case from rapidly progressive glomerulonephritis group.) HE, $\times 200$.

reactions, immune complex depositions were shown in the skin and blood vessels (Bullock et al., 1974; Quismorio et al., 1975; Turk and Bryceson, 1971; Wemambu et al., 1969). The aetiologic role of ENL reaction in the nephropathies in leprosy cannot be ignored, but in 6 patients without a past history of ENL reaction, mesangioproliferative glomerulonephritis was found when our study was over. It seems quite well established that proliferative glomerulonephritis belongs to the broad class of immune complex glomerulonephritis, as seen in the present study. According to Job et al. (1964), ENL has 3 phases. The first is an acute phase, with subacute and chronic phases following the first phase. This description is similar to an experimental disease called the BSA-rabbit system. The results of the studies on the BSA-rabbit system indicated that immune complex size is the main determinant of the site of location of circulating complexes within the glomerulus and thus of the nature of the glomerulopathy (Germuth and Rodriguez, 1973). In the acute BSA-rabbit system a single injection of antigen is followed by an acute diffuse glomerulonephritis as a result of antigen-antibody complexes formed in the antigen excess. There are 3 different phases of disappearance of circulating immune complexes and lesions. In ENL, the acute release of mycobacterial antigens in the circulation, as a result of either normal breakdown of bacilli or drug therapy, permits the formation of circulating immune complexes formed in antigen excess. Thus, an acute diffuse glomerulonephritis may develop, as in cases reported by Drutz and Gutman $(1972,1973)$ and Date and Johny (1975). Haematuria and proteinuria are common findings in ENL, but do not indicate current renal disease, and the lesions may show a complete recovery within a period of several months if the 
patient has a high antibody response. In the low antibody response form, it appears morphologically as a rapidly progressive glomerulonephritis, as shown in a case presented here. Clinically, there was a rapidly evolving renal failure terminating in irreversible uraemia in a few months. These kind of lesions found in patients with ENL resemble those produced in the acute BSA-rabbit system, and they are probably produced by the same mechanism.

Chronic glomerular lesions may develop when animals are exposed to prolonged antigen. In these animals, diffuse mesangioproliferative glomerulonephritis is found in a high proportion of those experiments which show a moderate antibody response, and circulating complexes are less soluble. Complexes developed in the moderate antibody response are localized primarily in the mesangium with occasional extension into the contiguous capillary walls. The mesangium responds eventually in the expansion of the mesangial cells and matrix that contain the deposited immune complexes into the capillary walls. In the present study, fluorescence and electron microscopy findings were attributed to the fact that the deposits are less soluble immune complexes and our patients with or without ENL had moderate immune response because the deposits were found primarily in the mesangium.

In the study of Johny et al. (1975), no definite relationship could be observed between the occurrence of glomerulonephritis and the presence of ENL. In 50\% of the cases reported by Mittal et al. (1972), consisting of 6 lepromatous without ENL, 4 lepromatous with ENL and 5 non-lepromatous, histologic changes were seen in the kidneys. These results are very close to ours. In our cases, none of the 3 patients with ENL and 5 patients without ENL had any renal lesions, this finding may be related to the very high antibody response of these patients. The complexes formed are very large and are rapidly removed from the circulation by the RES, when there is a large amount of circulating antibody. These kinds of complexes are not responsible for glomerular lesions.

In this study, we have seen cases in which the patients with or without ENL had mesangioproliferative glomerulonephritis, which was established by three microscopical methods. According to our opinion, the incidence of renal involvement in leprosy depends mainly on the antibody response of the patients, thus the size of immune complexes. These results may be related to the selection of the patients, since the patients were selected at random and our findings are similar to the results of the studies made by Johny et al. (1975) and Mittal et al. (1972) who chose their patients at random as well.

In one biopsy specimen, granular deposits in the epithelium of proximal tubuli were observed with anti-human IgA. The pathological significance of tubular epithelium deposits is unknown, since it was not accompanied by any apparent lesion observable by light microscopy.

\section{Acknowledgements}

The author wishes to thank Dr T. Saylan, Director of Bakırkoy Leprosy Sanatorium, Istanbul, Turkey. I also wish to thank Dr N. Koçak, Dr E. Ozdogan and Dr T. Erbengi, Istanbul Faculty of Medicine, for performing the necessary laboratory studies. 


\section{References}

Bernard, J. C. (1971). Estudio anatomopathologica de la distribucion de amiloidosis. Leprologia $16,15$.

Brusco, C. M. and Masanti, J. G. (1963). Causes of death of leprosy patients; influence of lepra reactions and renal disease. Int.J.Lepr. $31,14$.

Bullock, W. E., Callerame, M. L. and Panner, B. J. (1974). Immunohistologic alteration of skin and ultrastructural changes of glomerular basement membranes in leprosy. Am. J. trop. Med. Hyg. 23, 81.

Date, A. and Johny, K. V. (1975). Glomerular subepithelial deposits in lepromatous leprosy. Am. J. trop. Med. Hyg. 24, 853.

Drutz, D. J. and Gutman, R. A. (1972). The kidney in leprosy: an immunologic target organ. Int.J. Lepr. 40, 217.

Drutz, D. J. and Gutman, R. A. (1973). Renal manif estations of leprosy. Am. J. trop. Med. Hyg. 22, 496.

Germuth, F. G., Jr. and Rodriguez, E. (1973). Immunopathology of the Renal Glomerulus. Little, Brown and Company, Boston.

Gokhale, B. B. and Kurkure, N. B. (1958). Phenol red excretion test of kidney function in leprosy patients. Ind.J. med. Sci. 12, 331 .

Granells, M. (1968). Renal lesions in leprosy. Int. J. Le pr. 36, 645.

Gutman, R. A., Lu, W.-H. and Drutz, D. J. (1973). Renal manif estations of leprosy. Am.J. trop. Med. Hyg. 22, 223.

Iveson, J. M. I., McDougall, A. C., Leathem, A. J. and Harris, H. J. (1975). Lepromatous leprosy presenting with polyarthritis, myositis, and immune complex glomerulonephritis. Br. med.J. 3, 619.

Job, C. K., Gude, S. and Macaden, V. P. (1964). Erythema nodosum leprosum. Int. J. Lepr. 32, 177.

Johny, K. V., Karat, A. B. A., Rao, P. S. S. and Date, A. (1975). Glomerulonephritis in leprosy. A percutaneous renal biopsy study. Lepr. Rev. 46, 29.

Kean, B. H. and Childress, M. E. (1942). A summary of 103 autopsies on leprosy patients on the Isthmus of Panama. Int.J.Lepr. 10, 51.

McAdam, K. P. W. J., Anders, R. F., Smith, S. R., Russel, D. A. and Price, M. A. (1975). Association of amyloidosis with ENL reactions and recurrent neutrophil leucocytes in leprosy. Lancet ii, 572.

Mitsuda, K. and Ogawa, M. (1937). A study of one hundred and fifty autopsies on cases of leprosy. Int.J.Lepr. 5, 53.

Mittal, M. M., Agarwal, S. C., Maheshwari, H. B. and Kumar, S. (1972). Renal lesions in leprosy. Arch. Path. 93, 8.

Quismorio, F. P., Rea, T. H., Levan, N. E. and Friou, G. T. (1975). Immunoglobulin deposits in lepromatous leprosy skin. Arch. Derm. 111, 331 .

Rea, T. H. and Levan, N. E. (1975). Erythema nodosum leprosum in a general hospital. Arch. Derm. $111,1575$.

Sachdev, J. C., Puri, D. and Bansal, S. (1969). Secondary amyloidosis in leprosy. Lepr. India 41, 73.

Shwe, T. (1971). Immune complexes in glomeruli of patients with leprosy. Lepr. Rev. 52, 282.

Thomas, G., Karat, A. B. A., Rao, P. S. S. and Prathapkumar, C. (1970). Changes in renal function during reactive phases of lepromatous leprosy. Int.J.Lepr. 38, 170.

Turk, J. L. and Bryceson, A. D. M. (1971). Immunological phenomena in leprosy and related diseases. Adv. Immun. 13, 209.

Waters, M. F. R., Turk, J. L. and Wemambu, S. N. C. (1971). Mechanism of reactions in leprosy. Int. J. Lepr. 39, 417.

Wemambu, S. N. C., Turk, J. L., Waters, M. F. R. and Rees, R. J. W. (1969). Erythema nodosum leprosum. A clinical manifestation of the Arthus phenomenon. Lancet ii, 933. 